\title{
REPERTÓRIO MUSICAL E ATIVIDADES NAS AULAS DO SUBPROJETO DO PIBID "MUSICANDO A ESCOLA"
}

\author{
William Albert N de C Silva ${ }^{1}$; Simone Marques Braga ${ }^{2}$; \\ 1. Bolsista PIBIC/FAPESB, Graduando em Licenciatura em Música, Universidade Estadual de Feira de Santana, \\ e-mail: abert.soul@gmail.com \\ 2. Orientador, Departamento de Letras e Artes, Universidade Estadual de Feira de Santana, e-mail: \\ moninhabraga@gmail.com
}

PALAVRAS-CHAVE: Repertório Musical; Diversidade; PIBID.

\section{INTRODUÇÃO}

A partir do momento que pensamos em fazer música, automaticamente também pensamos em um repertório, logo, podemos afirmar que a prática musical está associada a este repertório. Sendo assim, a utilização do mesmo na prática pedagógica musical poderá abranger um grande número de conteúdos, a exemplo do contexto histórico, célula rítmica, gênero musical, melodia, timbre, instrumentos musicais e atividades de performance/execução, apreciação, composição/criação, literatura e técnicas, como destaca o Modelo C(L)A(S)P de Swanwick (1979). Desta forma, a seleção do repertório torna-se um elemento estruturante no processo de ensino e aprendizagem musical na escola.

Swanwick propõe parâmetros para a educação musical, identificando cinco diferentes formas de vivenciar experiências musicais, a partir das atividades de Composition, Literature, Audition, Skills Abilities e Performance que, traduzidas para o português, segundo Alda de Oliveira e Liane Hentschke (2003), temos Composição, Literatura, Apreciação, Técnica e Execução. As atividades de composição, apreciação e performance estão diretamente associadas ao fazer musical, tendo o autor as definido como atividades centrais. Já literatura e técnica são atividades subordinadas e devem contribuir no desenvolvimento musical das atividades centrais.

Tendo em vista que cada educando traz consigo uma vivência musical, é necessário que o professor utilize repertórios diversificados, inclusive provenientes do contexto sociocultural do discente. Sendo assim, defendendo um ensino musical escolar que contemple a diversidade existente na sala de aula por meio do seu repertório, esta pesquisa teve como objetivo geral identificar e catalogar quais músicas são trabalhadas nas aulas do Subprojeto Musicando a Escola do PIBID da UEFS, e quais as atividades foram desenvolvidas através deste repertório, relacionando-as ao modelo C(L)A(S)P. Quanto aos objetivos específicos, pretendeu-se verificar os gêneros musicais abordados; identificar os critérios e fatores motivadores para a escolha do repertório; verificar os níveis e especificidades da interação discente $\mathrm{x}$ docente relacionados ao repertório identificado; verificar as atividades desenvolvidas a partir do repertório identificado relacionadas à Modelo $\mathrm{C}(\mathrm{L}) \mathrm{A}(\mathrm{S}) \mathrm{P}$; catalogar as atividades analisadas para efeito de posteriores consultas e utilizações.

Os resultados aqui obtidos verificam uma prática pedagógica pautada no diálogo entre professor e aluno na construção do repertório na busca por contemplar a diversidade. 
Tais repertórios se adequam a realidade de cada escola, ao possibilitar aos alunos vivências musicais diversas. A partir dessa pesquisa também foi desenvolvido o Trabalho de Conclusão de Curso sobre a orientação do Prof. Dr. Luciano Almeida.

\section{METODOLOGIA}

De acordo com os objetivos propostos nesta pesquisa, esta se enquadra como uma investigação de abordagem qualitativa, porque investiga objetos intrínsecos nas relações humanas, mais especificamente, a interação professor x aluno e sua relação com o repertório musical.

O contexto de investigação foi o subprojeto Musicando a Escola, que faz parte do PIBID - UEFS. As escolas parceiras são o Centro Integrado de Educação Municipal Prof. Joselito Falcão de Amorim, o Centro Integrado de Educação Assis Chateaubriand, o Colégio Modelo Luís Eduardo Magalhães e o Instituto de Educação Gastão Guimarães. A intervenção dos bolsistas do Musicando a Escola acontece no horário de aula da disciplina “Artes". Além das atividades de ensino, os bolsistas também participam das Atividades Complementares (AC), onde, semanalmente há um encontro para o planejamento e avaliação das práticas pedagógicas desenvolvidas, com a presença de todos os envolvidos.

O instrumento para coleta de dados adotado foi a entrevista semi-estruturada. Sendo assim, em linhas gerais, as questões buscaram identificar qual o tipo de repertório utilizado, que fatores influenciaram a escolha deste, qual a interação discente com o repertório, qual a relação professor x aluno na mediação do conhecimento e quais são as atividades realizadas, a partir do modelo $\mathrm{C}(\mathrm{L}) \mathrm{A}(\mathrm{S}) \mathrm{P}$.

Para a aplicação das perguntas foi adotada a técnica de abordagem de Grupo Focal. De acordo com Backes et al (2011), o grupo focal é uma técnica de coleta de dados, que parte da interação do grupo, podendo trabalhar com uma ampla problematização ou apenas um tema específico. As entrevistas ocorreram em quatro momentos, em horários e dias distintos, uma para cada escola, gravadas utilizando um smartphone. Em seguida as gravações foram transcritas, para facilitar a análise e a organização dos dados.

No processo de análise, os dados coletados nas entrevistas e nos projetos pedoagógicos foram organizados em gráfico e em duas tabelas para facilitar a comparação das especificidades das atividades implementadas no Musicando a Escola, que podem ser encontrados em anexo. Após organização desses dados foram feitas descrições sobre cada gráfico e tabela, estabelecendo diálogos entre os depoimentos dos entrevistados e a bibliografia consultada. Este processo foi conduzido com muita atenção, sendo necessário retornar aos áudios e às transcrições diversas vezes, para compreender as entrelinhas dos depoimentos. 


\section{RESULTADOS}

Sobre a diversidade, verificamos que o universo musical trazido pelos alunos foi contemplado, resultando numa prática musical significativa para estes. A diversidade também contemplou a inserção de diferentes contextos culturais nas músicas utilizadas em atividades escolares, buscando a ampliação e/ou transformação deste universo. Cabe ao docente atenção ao trabalhar com a diversidade para que não se estabeleça hierarquias e o contexto musical do discente não seja apenas uma ponte para se chegar a uma "música superior".

Sobre o repertório verificou-se uma concordância entre a prática dos grupos entrevistados e os fundamentos abordados na revisão bibliográfica. Tal concordância aponta para que os fatores na escolha do repertório sejam pautados em três ações: contemple o contexto do aluno; busque uma ampliação do repertório discente e contemple a diversidade musical, tanto no que diz respeito às suas variações de gênero, como nas suas naturezas instrumental e vocal.

Sobre as atividades, os grupos buscaram um equilíbrio entre os parâmetros, preocupados em contemplar diversas vivências musicais, relacionando o fazer musical ao desenvolvimento de habilidades e saberes coerentes com a realidade das escolas de atuação.

Quanto a Composição percebe-se que este parâmetro é utilizado dentro de três perspectivas: improvisação, arranjos rítmicos e a criação rítmica/melódica. Em ambas perspectivas se faz necessário o desenvolvimento da criatividade e da organização de elementos sonoros, carregados de significados. Tais elementos são adquiridos por meio da apreciação.

O parâmetro Apreciação está presente em todas as atividades, o que nos faz pensar que para os grupos a apreciação também é atividade central e fundamental para o desenvolvimento musical do aluno, como defendem França e Swanwick (2002). Tais atividades proporcionam aos alunos capacidades de ouvirem a si mesmos e aos outros colegas. Na Apreciação, também são apresentadas músicas para introduzir o conteúdo proposto e estabelecer relação entre o gosto dos alunos, para que a performance seja carregada de sentido.

Quanto à Performance, foram desenvolvidas atividades que vivificaram o material sonoro, por mais simples que ele fosse, por meio da expressividade e uma carga de significados. Observa-se que este parâmetro é determinante nas atividades de culminância dos projetos desenvolvidos nas escolas. Já o parâmetro Técnica perpassou pelos demais, pois na prática musical foram ofertados orientações de técnicas que facilitassem a produção do som.

No parâmetro Literatura, foram desenvolvidas atividades que continham informações sobre música, referentes aos termos e nomenclatura, notação musical, o contexto social e histórico dos gêneros musicais, conteúdo de letras, temas transversais (preconceito, racismo, religião, inclusão, etc).

Sobre a atuação observa-se uma consistência no discurso dos bolsistas que estavam há mais tempo no Musicando a Escola e, consequentemente, também eram mais veteranos 
no Curso de Licenciatura em Música, porque os conteúdos pedagógicos musicais são abordados do meio do curso em diante. Embora todos participaram das Atividades de Formação, onde foram trabalhadas as leituras e minicursos voltados para prática em sala de aula e conteúdos em música, a maturidade e a consciência só é adquirida na experiência em sala de aula e conforme avançam na graduação.

\section{CONSIDERAÇÕES FINAIS}

Os resultados apontam para a importância da seleção do repertório em práticas pedagógicas musicais, sinalizando para critérios e fatores que devem ser levados em consideração na hora da escolha. Assim como apresenta reflexões acerca das práticas do subprojeto e o curso de licenciatura em música da UEFS.

Por fim, este trabalho apresenta uma relevância para os professores e licenciandos que pretendem trabalhar com música em suas aulas, ao passo que, servirá como base de discussões para criação de projetos pedagógicos que dialoguem com a diversidade dos diferentes contextos da comunidade escolar, com a valorização e ampliação dos repertórios existentes na escola nas mais variadas formas de vivenciar a música e que, sobre tudo, contribuam para formação de cidadãos críticos e sensíveis às relações humanas.

\section{REFERÊNCIAS}

BACKES, D. S. et al. Grupo focal como técnica de coleta e análise de dados em pesquisas qualitativas. O Mundo da Saúde, São Paulo, v. 35, n. 4, p. 438-442, 2011.

FRANÇA, C. C.; SWANWICK, K. Composição, apreciação e performance na educação musical: teoria, pesquisa e prática. Em Pauta, v.13, n.21. Porto Alegre: UFRGS, 2002.p.5-41.

QUEIROZ, L. R.. Educação musical e cultura: singularidade e pluralidade cultural no ensino e aprendizagem da música. Revista da ABEM, Porto Alegre, v. 10, p. 99-107, mar. 2004.

QUEIROZ, L. R.. Diversidade musical e ensino de música. Educação Musical Escola, TV escola. Salto para o futuro; Ano XXI Boletim 08 - Junho 2011.

SWANWICK, K. A Basis for Music Education. London: Routledge, 1979. 